\title{
Allelic and genotypic frequencies of the DMRT3 gene in the Brazilian horse breed Mangalarga Marchador and their association with types of gait
}

\author{
F.O. Bussiman 1 , B.A. dos Santos ${ }^{2}$, B.C. Abreu Silva ${ }^{3}$, B.C. Perez ${ }^{1}$, \\ G.L. Pereira ${ }^{2}$, L.A.L. Chardulo ${ }^{2}$, J.P. Eler ${ }^{3}$, J.B.S. Ferraz ${ }^{3}$, E.C. Mattos ${ }^{3}$, \\ R.A. Curi ${ }^{2}$ and J.C.C. Balieiro ${ }^{4}$ \\ ${ }^{1}$ Departamento de Zootecnia, Faculdade de Zootecnia e Engenharia de \\ Alimentos, Universidade de São Paulo, Pirassununga, SP, Brasil \\ ${ }^{2}$ Departamento de Melhoramento de Nutrição Animal, Faculdade de \\ Medicina Veterinária e Zootecnia, Universidade Estadual de São Paulo, \\ Botucatu, SP, Brasil \\ ${ }^{3}$ Grupo de Melhoramento Genético e Biotecnologia, Departamento de \\ Medicina Veterinária, Faculdade de Zootecnia e Engenharia de Alimentos, \\ Universidade de São Paulo, Pirassununga, SP, Brasil \\ ${ }^{4}$ Departamento de Nutrição e Produção Animal, Faculdade de Medicina \\ Veterinária e Zootecnia, Universidade de São Paulo, Pirassununga, SP, \\ Brasil
}

Corresponding author: F.O. Bussiman

E-mail: fernando.bussiman@usp.br

Genet. Mol. Res. 18 (1): gmr18217

Received November 20, 2018

Accepted February 01, 2019

Published February 25, 2019

DOI http://dx.doi.org/10.4238/gmr18217

ABSTRACT. The DMRT3 gene has been described as the main gene
influencing gait in horses; however, most studies have examined its
effects by comparing information from trotted and gaited individuals.
Within the Brazilian Mangalarga Marchador breed, animals can
present two types of gaits (marcha batida and marcha picada), which
differ in the movement form - diagonal (marcha batida) or lateral
(marcha picada). We examined a possible association of the
g.22999655C $>$ A DMRT3 SNP with the type of gait, in this two-gaits
breed. The relationship between individuals was calculated for the
two phenotypic groups, as well as the inbreeding coefficient and its
trend over generations. The allelic and genotypic frequencies were
estimated based on genotype data from 310 horses ( 205 marcha 
batida; 105 marcha picada).Two threshold models were used to determine the proportion of phenotypic variance explained by DMRT3 genotypes. The average coancestry for animals with marcha batida was $0.04 \pm 0.00$, whereas in marcha picada it was $0.05 \pm 0.01$ (higher than the population mean of $0.04 \pm 0.00$ ). The inbreeding coefficient was $1.71 \%$ and $3.48 \%$ for marcha batida and marcha picada animals, respectively. Effects of the DMRT3 gene ranged from 9.94 to $10.77 \%$ (as a proportion of phenotypic variance) when included as an uncorrelated random effect and as a covariable, respectively. The genotypic frequencies of the DMRT3 and the patterns of kinship and inbreeding could be a result of selection in this breed, resulting in statistical confusion between the DMRT3 effects and population structure.

Key words: Kinship; Inbreeding; Variance explained; SNP effect; Gait

\section{INTRODUCTION}

The Mangalarga Marchador is a Brazilian horse breed that originated from animals brought by the European colonizers and selected over the years for specific gait and morphological aspects (Mota and Prado, 2005). In 1949, the Brazilian Mangalarga Marchador horse breeders association (ABCCMM) was founded, and today this breed figures in the first position in the number of registered animals in Brazil. Recently, this breed was declared as "the national breed". These horses are exported globally, achieving international importance (Fonseca et al., 2017). In the Brazilian Mangalarga Marchador breed, animals present two types of gaits, named marcha batida (MB) and marcha picada (MP), which differ in the movement form - diagonal or lateral, respectively.

By definition, the gaits called "marcha" in Brazil are dissociated gaits, which are recognized by the moments of triple-limb support. The dissociation means that each limb is in a different phase during the locomotion of the horse. According to Nicodemus and Clayton (2003), both gaits in the Mangalarga Marchador are four-beat gaits; which can be understood as an accelerated form of walking. Due to this dissociation, gaited horses can perform various support types during locomotion, and some of these types are predominant in each gait. The time of diagonal support in the MB gait is longer than in MP. Whereas, in MP the lateral support is longer. Both of these gaits have triple-limb support interleaved with bipedal support.

According to Manso Filho et al. (2015), in recent years distinct genes have been studied with the objective to assess the genetic origins of the types of gait. Among the most promising candidate genes, DMRT3 is described as responsible for influencing the patterns of left and right limbs, as well as thoracic and pelvic coordination (Andersson et al., 2012). Andersson et al. (2012), Promerová et al. (2014), and Patterson et al. (2015), reported that the mutant allele A of g.22999655C>A DMRT3 SNP is the most frequent in gaited horses, whereas in trot animals the wild variant (C) has a higher frequency. Moreover, allele A has been associated with good quality of pace and gait, when compared to animals with genotype CC (Andersson et al., 2012; Jäderkvist et al., 2015). 
Recent studies (Promerová et al., 2014; Manso Filho et al., 2015; Patterson et al., 2015; Pereira et al., 2016; Fonseca et al., 2017) reported genotypic and allelic frequencies for g.22999655C>A SNP, and found that marcha picada animals have a higher frequency of the A allele compared with animals exhibiting marcha batida. However, this relationship remains uncertain, and the genotypic frequencies observed suggest that although DMRT3 is associated with gait, it would not be the exclusive causative variant for the different types of gait in Mangalarga Marchador horses. To better understand its role, we examined the relationship between the DMRT3 gene and the type of gait in Mangalarga Marchador horses; we also investigated the patterns of kinship and inbreeding as a function of the observed phenotypes and genotypes.

\section{MATERIAL AND METHODS}

\section{Animals and pedigree}

Blood samples were collected from 310 horses (105 MP and $205 \mathrm{MB}$ ) in various properties $(\mathrm{N}=14)$ across São Paulo and Minas Gerais states in Brazil and during the $36^{\text {th }}$ National Mangalarga Marchador show, attempting to assess the diversity of this breed in Brazil. This study was conducted according to ethical principles in animal experimentation (UNESP, Botucatu, Brazil; Approval number 29/2017). Pedigree information for all phenotyped individuals was collected from the public website of the ABCCMM. The complete pedigree file considered for this study contained 3,172 horses with an average relatedness of 0.007 (excluding self-relationships) and an average equivalent complete generation of 2.02 (maximum of 6.23). In total, the pedigree file contained 931 stallions and 1880 mares, with an average number of progenies of 2.56 and 1.27 for stallions and mares, respectively. The average family size was 2.25 ; it ranged from 2 to 7 and the number of full-sib groups was 130. The number of animals per generation is shown in Figure 1.

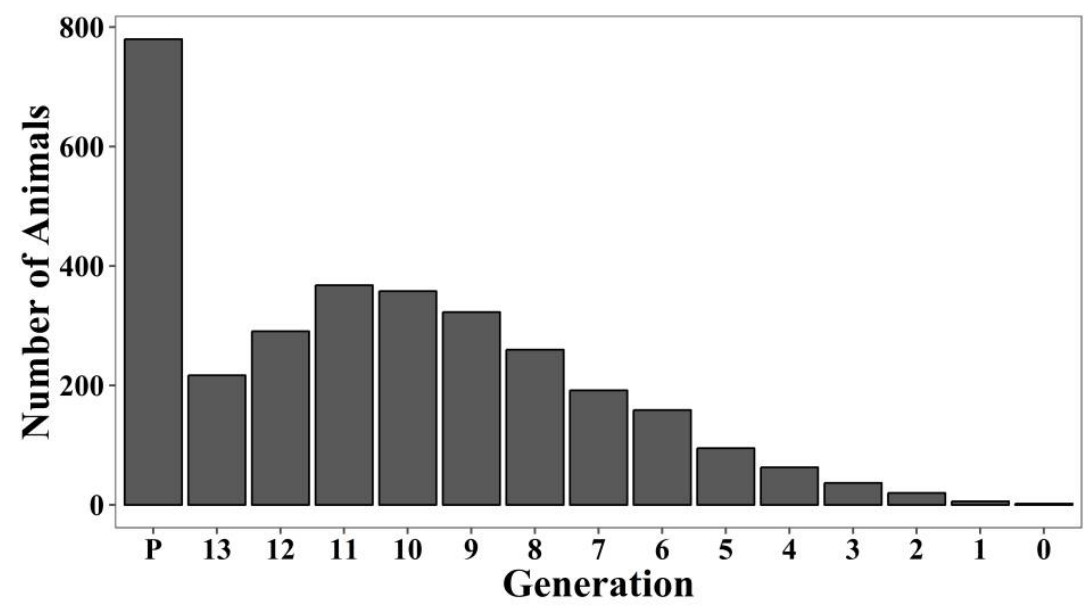

Figure 1. Number of Mangalarga Marchador horses per each generation of pedigree $(\mathrm{P}=$ parental generation Founders; $0=$ most recent generation). 
The DNA was obtained for each animal with the Illustra Blood GenomicPrep Mini Spin Kit (GE Healthcare), following the manufacturer's specifications. The concentration and purity were set to be $10 \mathrm{ng} / \mu \mathrm{L}$ and 1.7 (260/280 ratio), respectively. After DNA extraction, all animals were genotyped for the g.22999655C>A SNP by PCR-RFLP according to Pereira et al. (2016).

\section{Gait determination}

For each animal, the information on the type of gait was accessed by watching a video of the animal in motion (at liberty and mounted) and by documents of the records of the breeders showing the type of gait. The competition information on the ABCCMM website was checked to confirm the category in which the animal competes (MP or MB). The person who watched the filming was always the same, and the gait was confirmed by visually verifying that the displacement of the animal involved predominantly lateral (MP) or diagonal (MB) movements.

\section{Kinship, inbreeding, and allele frequencies}

The genetic relationship between phenotyped animals and the inbreeding coefficient (F) for each were calculated. The numerator relationship matrix (NRM, Emik and Terrill, 1949; Henderson, 1975; Henderson, 1976) was constructed using the CFC software (Sargolzaei et al., 2006), showing the expectancy of genetic connection between all pedigreed individuals. Animals were grouped according to phenotype (MB or MP) and genotypes (AA, CA and CC), and kinship coefficients were calculated within and between groups. The $\mathrm{F}$ coefficient was used to identify possible trends of inbreeding over generations. Allelic and genotypic frequencies were estimated by counting alleles and genotypes within each phenotype group and divided by the total information, i.e., the total number of alleles (or genotypes). Additionally, the Hardy-Weinberg equilibrium test was performed for the genotypes.

\section{DMRT3 effect}

Two categorical threshold mixed models were proposed to estimate the effect of $D M R T 3$ on the type of gait:

$$
\begin{gathered}
Y_{i j k}=\beta_{1} \text { Ageclass }+\beta_{2} \text { DMRT3 }+ \text { Farm }_{i}+u_{j}+e_{k} \\
Y_{i j k l}=\beta_{1} \text { Ageclass }+ \text { Farm }_{i}+u_{j}+\text { DMRT }_{k}+e_{l}
\end{gathered}
$$

where $\beta_{1}$ is the regression coefficient for the covariate Ageclass (class of age) in both models; $\beta_{2}$ is the regression coefficient of the DMRT3 genotype (coded as AA $=1, \mathrm{CA}=2$ and $\mathrm{CC}=3$ ) in model $1 ; D M R T 3$ genotype (identically coded) was treated as a random effect (model 2), with $D M R T 3 \sim N\left(0, I \sigma_{D M R T 3}^{2}\right) ;$ Farm $_{i}$ represents the systematic fixed effect of the $\mathrm{i}^{\text {th }} \mathrm{Farm} ; u_{j}$ represents the random effect of the $\mathrm{j}^{\text {th }}$ animal, with variance as $u \sim N\left(0, A \sigma_{u}^{2}\right)$, where $\mathrm{A}$ is the NRM and $e$ represents the random residual terms, in which $e \sim N\left(0, I \sigma_{e}^{2}\right)$. 
The analyses were implemented using a Bayesian framework. Thus, inferences were made through the posterior distributions of the parameters. Based on the Bayes rule, the posterior density of unknown parameters is $p(\theta \mid Y) \propto p(Y \mid \theta) p(\theta)$, where $\theta$ represents the collection of all unknown parameters in the models, $p(\theta)$ is the prior distribution for $\theta$, and $p(\theta \mid Y)$ is the posterior distribution of the unknown parameters. The joint prior distribution of the parameters was defined as: $p(\theta) \propto p\left(u \mid \sigma_{u}^{2}\right) p\left(\sigma_{u}^{2}\right) p\left(\sigma_{e}^{2}\right), \quad$ this is: $p(\theta) \propto N\left(u \mid 0, A \sigma_{u}^{2}\right) X^{-2}\left(\sigma_{u}^{2} \mid d f_{u}, S_{u}\right) X^{-2}\left(\sigma_{e}^{2} \mid d f_{e}, S_{e}\right)$, where $X^{-2}(. \mid d f .$, . $)$ is a scaled inverse $X^{-2}$ distribution with $d f$ and scale parameter $S$.

Analyses were performed using the THRGIBBS 1F90 software (Misztal et al. 2002); 2,000,000 of samples were generated in a single chain, assuming a burn-in period of 1,000,000 and a thinning interval of 100. Thus, all inferences were made over 10,000 samples from the posterior distribution. Convergence of the MCMC chains was verified by applying the Geweke test (Geweke, 1992) and the Heidelberger-Welch test (Heidelberger and Welch 1983), using the 'coda' package (Plummer et al., 2006) from R Software (R Core Team, 2016).

In the case in which DMRT3 genotypes were treated as a covariable (1), the proportion of phenotypic variance explained was calculated according to Shim et al. (2015):

$$
P V E=\frac{2 \widehat{\beta}^{2} p(1-p)}{2 \widehat{\beta}^{2} p(1-p)+(\operatorname{se}(\widehat{\beta}))^{2} 2 N p(1-p)}
$$

were, $P V E$ is the proportion of phenotypic variance explained; $\hat{\beta}$ is the estimated coefficient for the effect of DMRT3; $p$ is the minor allele frequency for DMRT3; $\operatorname{se}(\hat{\beta})$ is the standard error for the estimated coefficient and $N$ is the sample size.

In the case were DMRT3 genotypes were treated as an uncorrelated random effect (model 2) the proportion of phenotypic variance explained was calculated as:

$$
P V E=\frac{\sigma_{D M R T 3}^{2}}{\sigma_{u}^{2}+\sigma_{D M R T 3}^{2}+\sigma_{e}^{2}}
$$

where $\sigma_{D M R T 3}^{2}$ is the estimated variance of the DMRT3 genotype; $\sigma_{u}^{2}$ the additive genetic variance and $\sigma_{e}^{2}$ is the residual variance.

\section{RESULTS}

\section{Kinship, inbreeding and allele frequencies}

Graphical visualization of the NRM (data not shown) revealed differences between pairwise-relationships within gait groups. The average coefficients of co-ancestry, considering all pedigreed population and for animals without phenotypes were $0.04 \pm 0.00$ and $0.06 \pm 0.00$, respectively. The only phenotypic group that presented a co-ancestry coefficient greater than the pedigreed sample average $(0.05 \pm 0.01)$ was the MP group (Table 1). 
Table 1. Descriptive statistics of the Mangalarga Marchador horse kinship coefficient.

\begin{tabular}{lrrrrr}
\hline \multicolumn{1}{c}{ Set of Data } & Mean & Min & Max & \multicolumn{1}{c}{ SD } & \multicolumn{1}{c}{ N } \\
\hline Total Pedigree & 0.04 & $9.54 \times 10^{-07}$ & 1.06 & 0.06 & 3172 \\
Marcha Batida & 0.04 & $3.81 \times 10^{-06}$ & 0.97 & 0.07 & 205 \\
Marcha Picada & 0.05 & $9.54 \times 10^{-07}$ & 0.81 & 0.09 & 105 \\
Non-phenotyped & 0.06 & $3.81 \times 10^{-06}$ & 0.84 & 0.09 & 2862 \\
\hline
\end{tabular}

SD: standard deviation; N: number of animals.

The mean F for MP and MB individuals was $3.48 \%$ and $1.71 \%$, respectively. Differences in the average $\mathrm{F}$ between the two groups were significant based on the $T$ test $(\mathrm{P}<0.001)$. All inbred animals presented a decreasing trend for $\mathrm{F}$, but these trends did not differ within each phenotypic group (Figure 2). Additionally, the proportion of animals in classes from 5 to $20 \%$ of $\mathrm{F}$ was greater in MP than in MB animals (Table 3).

Table 2. Descriptive statistics of the Mangalarga Marchador horse in breeding coefficient.

\begin{tabular}{lrrrrr}
\hline \multicolumn{1}{c}{ Set of Data } & \multicolumn{2}{c}{ Mean } & Min & \multicolumn{1}{c}{ Max } & \multicolumn{2}{c}{ SD } & \% of total \\
\hline Total Pedigree & 0.015 & 0.000 & 0.410 & 0.040 & 21.31 \\
Marcha Batida & 0.017 & 0.000 & 0.410 & 0.050 & 40.49 \\
Marcha Picada & 0.035 & 0.000 & 0.310 & 0.050 & 75.24 \\
Non-phenotyped & 0.009 & 0.000 & 0.310 & 0.040 & 0.31 \\
\hline
\end{tabular}
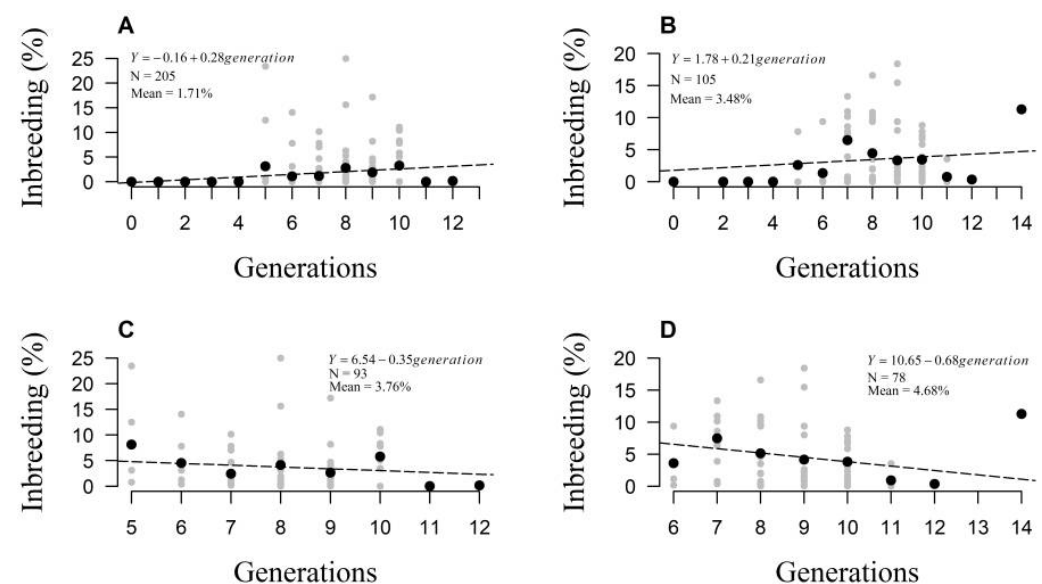

Figure 2. Inbreeding trend over generations according to the type of gait and total or inbred Mangalarga Marchador horses. A: all marcha batida animals $(\mathrm{P}=0.012)$; $\mathrm{B}$ : all marcha picada animals $(\mathrm{P}=0.300)$; $\mathrm{C}$ : inbred marcha batida animals $(\mathrm{P}=0.046)$ and $\mathrm{D}$ : inbred marcha picada animals $(\mathrm{P}=0.045)$.

Table 3. Number of Mangalarga Marchador horses per inbreeding category and percentage of each class.

\begin{tabular}{|c|c|c|c|c|c|c|}
\hline \multirow{2}{*}{$\mathrm{F}$ categories $(\%)$} & \multicolumn{2}{|c|}{ Total Pedigree } & \multicolumn{2}{|c|}{ Marcha Batida } & \multicolumn{2}{|c|}{ Marcha Picada } \\
\hline & $\mathbf{N}$ & $\%$ of total & $\mathbf{N}$ & $\%$ of total & $\mathbf{N}$ & $\%$ of total \\
\hline 0.00 to 2.50 & 2757 & 86.92 & 168 & 81.95 & 65 & 61.90 \\
\hline 2.50 to 5.00 & 85 & 2.68 & 14 & 6.83 & 11 & 10.48 \\
\hline 5.00 to 10.00 & 141 & 4.45 & 13 & 6.34 & 18 & 17.14 \\
\hline 10.00 to 15.00 & 99 & 3.12 & 5 & 2.44 & 7 & 6.67 \\
\hline 15.00 to 20.00 & 37 & 1.17 & 2 & 0.98 & 4 & 3.81 \\
\hline 20.00 to 25.00 & 4 & 0.13 & 1 & 0.49 & 0 & 0.00 \\
\hline$\geq 25.00$ & 49 & 1.54 & 2 & 0.98 & 0 & 0.00 \\
\hline Total & 3172 & 100 & 205 & 100 & 105 & 100 \\
\hline
\end{tabular}

$\mathrm{N}$ : number of animals. 
The observed frequency of the DMRT3 A allele for all phenotyped individuals was 0.47 (Figure 3A); it was more frequent within the group of MP individuals (0.93). The C allele was at a higher frequency in $\mathrm{MB}$ animals (0.77), which was also higher than in all phenotyped individuals (0.53-Figure 3A). Genotypic frequencies were $0.33,0.27$ and 0.40 (Figure 3B) for the AA, CA and CC genotypes, respectively (considering the data of all phenotyped animals). For the group of MB individuals, there was a higher frequency of heterozygous (0.34) and a very low frequency of homozygous AA (0.06) horses. Within the group of MP animals, the frequency of homozygous CC was zero, and homozygous AA was 0.87 . Thus, the frequency of heterozygous CA was 0.13 (Figure 3B). The P-value for the Hardy-Weinberg equilibrium test (HWE) for all animals was $\mathrm{P}=4.32 \times 10^{-16}$; for the MP animals it was 1.00 , and for MB animals it was 0.69 .

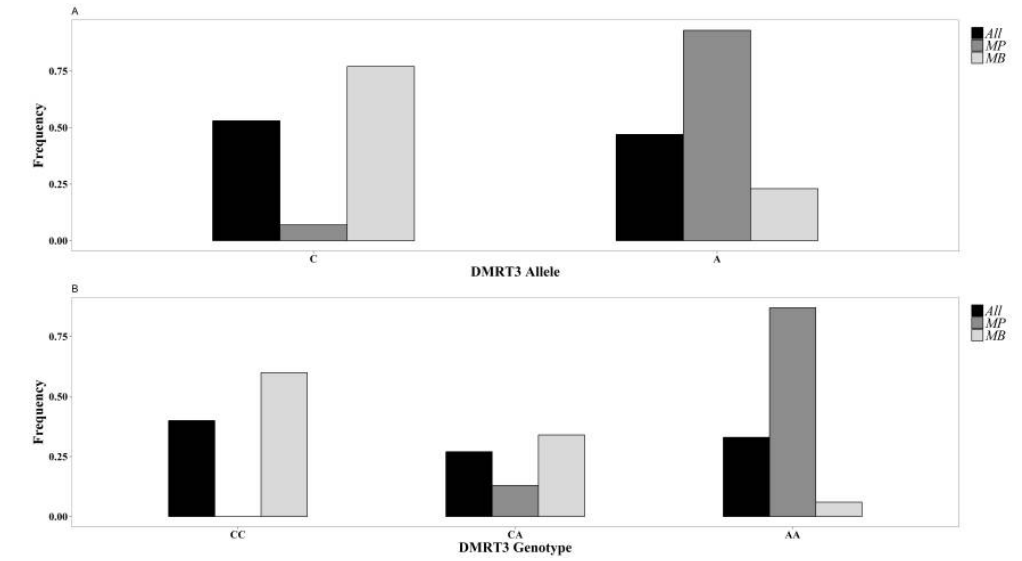

Figure 3. Allelic frequency of the g.22999655C $>$ A SNP according to the type of gait and in the entire population (A); Genotypic frequencies of the g.22999655C >A SNP according to the type of gait and in the entire population (B).

The average $\mathrm{F}$ was different among the genotypic groups within each gait type (Table 4). Whereas in the MP animals with AA genotype the F was $3.42 \%$, in the MB animals with AA genotype it was $0.74 \%$. The numbers of average equivalent generations were also different; in the MP animals with AA it was 1.83 , and in the MB animals with CC genotype it was 4.55 (Table 4). The average kinship in the MP animals with CA genotype was 0.11 , whereas it was 0.06 in the AA animals with the same gait. On the other hand, the AA animals exhibiting MB gait were the most related group, which could be due to subfamilies within the MB gait group.

Table 4. Number of Mangalarga Marchador horses, percent inbreeding, average number of discrete generations and average kinship coefficient per genotype of DMRT3 and according to gait type.

\begin{tabular}{cccccccc}
\hline Gait & Genotype & N & Inbreds & F & FI & DGE & f \\
\hline \multirow{3}{*}{ MP } & AA & 91 & 66 & $3.42 \%$ & $4.71 \%$ & 1.83 & 0.06 \\
& CA & 14 & 12 & $3.85 \%$ & $4.50 \%$ & -27 & - \\
& CC & - & - & - & - & - & -11 \\
\cline { 2 - 8 } MB & AA & 12 & 5 & $0.74 \%$ & $1.79 \%$ & 3.47 & 0.12 \\
& CA & 70 & 33 & $2.62 \%$ & $5.55 \%$ & 0.04 & 0.03 \\
\hline
\end{tabular}

$\mathrm{N}=$ number of animals; Inbreds = number of inbred animals; F and FI = inbreeding coefficient over all animals and inbreds, respectively; DGE $=$ average number of discrete generations and $\mathrm{f}=$ average kinship within the groups. 


\section{DMRT3 effect}

The graphical visualization of the trace plots for the two models did not present any trend or signs of non-convergence (data not shown). The Z-Scores of Geweke test for $\sigma_{u}^{2}$, $\sigma_{e}^{2}, h^{2}$, and DMRT3 posterior distribution ranged from -1.50 to 1.83. All estimates passed the Heidelberger-Welch stationary test ( $r$-Lag50 -Heidelberger and Welch 1983). A higher Z-Score value (1.83) was observed for the effect of DMRT3 when it was treated as a covariable, also presenting an autocorrelation of 0.08 , which was the greatest value observed for ther-Lag50. Posterior mean estimates (Highest-posterior density interval) for heritability were $0.45(0.03-0.83)$ and $0.26(0.00-0.28)$, for models 1 and 2 , respectively. The proportions of phenotypic variance explained by the DMRT3 were similar, $10.77 \%$ e and $9.94 \%$, when the genotypes were treated as a covariate and as a random effect, respectively (Table 5).

Table 5. Posterior mean, median, highest-posterior density (HPD), Geweke's test (Z-Score) and autocorrelation (r-Lag50) for the effect of DMRT3 genotypes according to the treatment (covariable or random effect).

\begin{tabular}{|c|c|c|c|c|c|c|}
\hline \multirow{2}{*}{ DMRT3 } & \multirow{2}{*}{ Mean $^{1}$} & \multirow{2}{*}{ Median $^{1}$} & \multicolumn{2}{|c|}{ HPD Interval $^{1}$} & \multirow{2}{*}{$\begin{array}{l}\text { Geweke Z- } \\
\text { Score }\end{array}$} & \multirow{2}{*}{$r$-Lag50 } \\
\hline & & & $5 \%$ & $95 \%$ & & \\
\hline Covariate & 10.77 & 10.90 & 5.22 & 17.03 & 1.83 & 0.08 \\
\hline Random effect & 9.94 & 10.00 & 9.90 & 10.00 & -1.08 & -0.01 \\
\hline
\end{tabular}

${ }^{1}$ Values presented as a proportion of phenotypic variance.

\section{DISCUSSION}

As selection in the Mangalarga Marchador breed is mainly based on pedigree, the mating of important/champion animals and their relatives is a common practice among breeders. This fact may explain the observed differences of relatedness and $F$ within each type of gait. As a consequence of inbred mating based on the type of gait, the two groups are separated in the population.

The pattern of relatedness presented by MB animals could be associated with the great number of founders that also exhibited this same phenotype. The higher mean for the kinship in MP animals is related to the frequency of high relationship values within this group. The higher kinship values found in MP individuals has to do with present relatedness (more recent mating causing this kinship). Some breeders do prefer mating MB animals with MP (D. Zabotto Neto, Personal Communication, May 2017), which explains the genetic relatedness $(0.03)$ between these groups.

The mean $\mathrm{F}$ observed for the pedigree population that we examined (1.50\%) was very close to estimates based on the complete population of this breed (Costa et al., 2005; DeAssis et al., 2009). This shows that the group we studied is a representative sample of the Mangalarga Marchador population. Average F in inbred animals (7.10\%) was greater than found by these same authors, which resulted in some more inbred animals in the group we investigated, influencing the coefficient estimate. Higher F values in MP animals may have resulted from the higher frequency of pairwise-relationships, since this frequency is greater in MP than in MB animals. Patterson et al. (2015) reported higher values of inbreeding in MB animals (1.20\%) and lower in MP individuals (0.16\%), which was also reported by Manso Filho et al. (2015), who found $31.63 \%$ inbreeding in MB animals and $2.42 \%$ in MP. The higher values of $\mathrm{F}$ found in our study may also be associated with the presence of some 
"elite" animals in the MP group, which increases F, since in this breed, in general, top animals are highly inbred.

Since the trends were calculated within each gait group, the increase in inbreeding can be an alert for preferred mating for animals with the same gait. In other words, the increase in inbreeding implies an increase of the probability of related animals mating. If that relation is observed within each gait group, the preference for the same gait makes sense. This fact was not confirmed in MP animals, which presented the lowest trend $(0.21$ gain in $\mathrm{F}$ per generation - which was not significant $\mathrm{P}>0.05)$. The $\mathrm{F}$ trends in inbred individuals showed that $\mathrm{F}$ in $\mathrm{MB}$ animals $(-0.35 \mathrm{~F} /$ generation) will take more time to decrease from a certain level, whereas in MP animals ( $-0.68 \mathrm{~F} /$ generation) this decrease is more accentuated, generation after generation, which may be related to a reduction of the number of highly inbred animals.

As a consequence of this scenario (of kinship and inbreeding), the alleles that are related to the type of gait were differently fixed within each gait. The allele frequencies of DMRT3 found in this study were close to those reported by Promerová et al. (2014), Manso Filho et al. (2015), Patterson et al. (2015) and Fonseca et al. (2017), but the frequencies of $\mathrm{CC}$ genotypes in $\mathrm{MB}$ individuals were different 0.94, 0.85 and 0.93 (Manso Filho et al. 2015; Patterson et al. 2015; Fonseca et al. 2017, respectively), which is a result of the high frequency of heterozygous CA that we found in the MB gait group. The higher frequency of the CA genotype observed in our study may be an indication of the diverse origin of the sampled animals, which were sampled not only from the national horseshow but from many properties (from São Paulo and Minas Gerais states of Brazil).

We speculate that heterozygous animals presenting MB exist in the population, but due to a coincidence of sampling, they have not been adequately sampled. It is also plausible that animals with a specific genotype of DMTR3 have different quality gaits, so that they are not represented in the national competition and were not sampled by Patterson et al. (2015) and Fonseca et al. (2017). Another possibility is the fact that animals with specific DMRT3 genotypes prefer different types of gait at liberty (Staiger et al., 2016); this could be influenced by the evaluations of the gait of some sampled animals, which were evaluated at liberty. MB animals with AA genotype were found in our study, as previously observed by Manso Filho et al. (2015).

A consequence of HWE is the independence of the alleles within genotypes while the allelic frequencies remain constant, the P-value found for the population suggests a dependency of the alleles within the genotypes. Also, it may be a consequence of a nonrandom mating system, which would disseminate specific haplotypes (or alleles), increasing the frequency of the corresponding genotypes. The subpopulations of MP and MB animals were in HWE; however, when they were added together, they were not in HWE. The number of homozygotes was higher than expected. Consequently, heterozygotes were fewer in the total sample; this can indicate that selection within the MP animals is strongly related to the DMRT3 mutation. The selection based on the MP subpopulation probably is related to breeding animals selected based on phenotype and close relatives, increasing the relationship among the MP animals and as a consequence also increasing inbreeding.

The average number of equivalent complete generations in the CA animals with MP gait may indicate that the high kinship in this group was created in past generations. In the same way, kinship among MP animals with the AA genotype was more recent, since the number of equivalent complete generations was the lowest value observed in our study. 
This could be related to selection of MP animals; initially this was in the direction of the CA genotype; now the selection criterion is very closely related to the AA genotype. The numbers of complete generations being equivalent across the genotypes in the MB animals showed that the selection criterion on these animals is not related to one genotype. All kinship coefficients were related to past generations, and the low degree of kinship within each genotypic group may indicate the mating of animals from all genotypes. The high kinship among the MB animals with the AA genotype may indicate that these animals form a subfamily.

Considering that all the horses had their phenotype defined, which was confirmed by watching a movie of their movement (always by the same person), we speculate that this is evidence confirming the hypothesis of Patterson et al. (2015), who indicated that DMRT3 is associated with but does not completely determine the type of gait in Mangalarga Marchador horses.

The parameter estimates showed that gait type in Mangalarga Marchador horses has a low to moderate heritability, suggesting genetic determination. The effects of DMRT3 genotypes were very strong for this trait, though this may be a function of genotypic frequencies, due to inbreeding and kinship, since the differences in the proportions of homozygous (AA/CC) and heterozygous (CA) individuals in each phenotypic group was more related to the patterns of kinship and inbreeding than to gait type.

A strong influence of the DMRT3 gene on gait traits has been reported by various researchers (Fegraeus et al., 2015; Jäderkvist et al., 2015b; Ricard, 2015; Negro Rama et al., 2016), who found that some genotypes could also be related to better performance (AA, Fegraeus et al., 2015), trot at liberty (CC and CA, Jäderkvist et al., 2015) and negative effects on racing traits (CC, Ricard, 2015), explaining around 0.30 to $1.67 \%$ of additive genetic variance (Negro Rama et al., 2016).

\section{CONCLUSIONS}

We found that, despite the important role played by the DMRT3 gene in the coordination of the members of horses; its effects on the type of gait in Mangalarga Marchador breed are not yet clear. There is a pattern of kinship and inbreeding that could be affecting the genotypic frequencies of this gene. Marcha batida animals have higher frequencies of CC and CA genotypes of the DMRT3 gene; our study is the first that found a high frequency of genotype CA in this gait group phenotype. The genotypic frequencies of DMRT3 and the patterns of kinship and inbreeding could be a result of selection on this breed, causing statistical confusion between DMRT3 effects and population structure. Future studies of a genome-wide association between genetic markers and the type of gait could help explain how this trait is genetically determined.

\section{ACKNOWLEDGMENTS}

The authors thank the Brazilian Association of the Horse Breeders Mangalarga Marchador, and the Group of Genetic Improvement and Biotechnology of the University of São Paulo (GMAB-FZEA/USP) for their support in analyses. The São Paulo State Research Foundation (FAPESP - grant numbers 2016/17834-0, 16/19081-9 and 2014/07566-2) 
funded this research. This study was financed in part by the Coordenação de Aperfeiçoamento de Pessoal de Nível Superior - Brasil (CAPES) - Finance Code 001.

\section{CONFLICTS OF INTEREST}

The authors report that there are no conflicts of interest relevant to this publication.

\section{REFERENCES}

Andersson LS, Larhammar M, Memic F, Wootz H, et al. (2012). Mutations in DMRT3 affect locomotion in horses and spinal circuit function in mice. Nature 488: 642-646.

Costa MD, Bergmann JAG, Resende ASC and Fonseca CG (2005). Análise temporal da endogamia e do tamanho efetivo da população de eqüinos da raça Mangalarga Marchador. Arq. Bras. Med. Vet. Zootec. 57: 112-119.

DeAssis JB, DeLaat DM, Peixoto MG, Bergmann JA, et al. (2009). Genetic diversity and population structure in Brazilian Mangalarga Marchador horses. Genet. Mol. Res. 8: 1519-1524.

Emik LO and Terrill CE (1949). Systematic procedures for calculating inbreeding coefficients. J. Hered. 40: 51-55.

Fegraeus KJ, Johansson L, Maenpaa M, Mykkanen A, et al. (2015). Different DMRT3 genotypes are best adapted for harness racing and riding in finnhorses. J. Hered. 106: 734-740.

Fonseca MG, Ferraz GC, Lage J, Pereira GL, et al. (2017). A Genome-Wide Association Study Reveals Differences in the Genetic Mechanism of Control of the Two Gait Patterns of the Brazilian Mangalarga Marchador Breed. $J$. Equine Vet. Sci. 53: 64-67.

Geweke J (1992). Evaluating the accuracy of sampling-based approaches to the calculation of posterior moments. Bayesian Stat 4: 169-193.

Heidelberger P and Welch PD (1983). Simulation Run Length Control in the Presence of an Initial Transient. Oper. Res. 31: $1109-1144$.

Henderson ACR (1976). A Simple Method for Computing the Inverse of a Numerator Relationship Matrix Used in Prediction of Breeding Values. Biometrics 32: 69-83.

Henderson CR (1975). Rapid method for computing the inverse of a relationship matrix. J. Dairy Sci. 58: 1727-1730.

Jäderkvist K, Johansson L, Mykkänen A, Mäenpää M, et al. (2015). The DMRT3 “Gait keeper” mutation affects harness racing performance and riding traits in Finnhorses. J. Equine Vet. Sci. 35: 399.

Manso Filho HC, Cothran EG, Juras R, Gomes Filho MA, et al. (2015). Alelo DMRT3 mutante em equinos de marcha batida e picada das raças Campolina e Mangalarga Marchador. Ciência Veterinária nos Trópicos 18: 6-11.

Misztal I, Tsuruta S, Strabel T, Auvray B, et al. (2002). BLUPF90 and related programs (BGF90). Proceedings of the 7th World Congress on Genetics Applied to Livestock Production. pp 21-22.

Mota MDS and Prado RSA (2005). Estudo genético da pontuação total em equinos Mangalarga. Arch. Zootec. 54: 2530.

Negro RS, Valera M, Membrillo A, Gómez MD, et al. (2016). Quantitative analysis of short- and long-distance racing performance in young and adult horses and association analysis with functional candidate genes in Spanish Trotter horses. J. Anim. Breed Genet. Breed Genet. 133: 347-356.

Nicodemus MC and Clayton HM (2003). Temporal variables of four-beat, stepping gaits of gaited horses. Appl. Anim. Behav. Sci. 80: 133-142.

Patterson L, Staiger EA and Brooks SA (2015). DMRT3 is associated with gait type in Mangalarga Marchador horses, but does not control gait ability. Anim Genet 46: 213-215. doi: 10.1111/age.12273

Pereira GL, de Matteis R, Regitano LCA, Chardulo LAL, et al. (2016). MSTN, CKM, and DMRT3 Gene Variants in Different Lines of Quarter Horses. J. Equine Vet. Sci. 39: 33-37.

Plummer M, Best N, Cowles K and Vines K (2006). CODA: convergence diagnosis and output analysis for MCMC. $R$. News 6: 7-11.

Promerová M, Andersson LS, Juras R, Penedo MCT, et al. (2014). Worldwide frequency distribution of the "Gait keeper" mutation in the DMRT3 gene. Anim. Genet. 45: 274-282.

R Core Team (2016). R Development Core Team. R A Lang Environ Stat Comput 55: 275-286.

Ricard A (2015). Does heterozygosity at the DMRT3 gene make French trotters better racers? Genet. Sel. Evol. 47: 1-16. Sargolzaei M, Iwasaki H and Colleau JJ (2006). CFC: A tool for Monitoring genetic diversity. Proceedings of the 8th World Congress on Genetics Applied to Livestock Production. Belo Horizonte, pp 27-28.

Shim H, Chasman DI, Smith JD, Mora S, et al. (2015). A Multivariate Genome-Wide Association Analysis of 10 LDL Subfractions, and Their Response to Statin Treatment, in 1868 Caucasians. PLoS One 4: e120758..

Staiger EA, Abri MA, Silva CAS and Brooks SA (2016). Loci impacting polymorphic gait in the Tennessee Walking Horse. J. Anim. Sci. 94: 1377-1386. 